\title{
Single-grain Si thin-film transistors on flexible polyimide substrate fabricated from doctor-blade coated liquid-Si
}

\author{
J. Zhang, ${ }^{1, a)}$ M. Trifunovic, ${ }^{1}$ M. van der Zwan, ${ }^{1}$ H. Takagishi, ${ }^{2}$ R. Kawajiri, ${ }^{2}$ T. Shimoda,${ }^{2,3}$ \\ C. I. M. Beenakker, ${ }^{1}$ and R. Ishihara ${ }^{1}$ \\ ${ }^{1}$ Delft University of Technology, Delft Institute of Microsystems and Nanoelectronics (DIMES), Feldmannweg \\ 17, 2628CT, Delft, The Netherlands \\ ${ }^{2}$ Japan Science and Technology Agency, ERATO, SHIMODA Nano-Liquid Process Project, 2-5-3 Asahidai, \\ Nomi, Ishikawa 923-1211, Japan \\ ${ }^{3}$ School of Materials Science, Japan Advanced Institute of Science and Technology (JAIST), 1-1 Asahidai, \\ Nomi, Ishikawa 923-1292, Japan
}

(Received 13 March 2013; accepted 22 May 2013; published online 18 June 2013)

\begin{abstract}
Solution process of silicon will provide high-speed transistor fabrication with low-cost by, for example, roll-to-roll process. In this paper, a low-temperature process $\left(350^{\circ} \mathrm{C}\right)$ is reported for fabrication of high-quality Si devices on a polyimide substrate from doctor-blade coated liquid-Si. With this method, different semiconductor devices have been fabricated, reporting a carrier mobility of $460 \mathrm{~cm}^{2} / \mathrm{V} \mathrm{s}$ and $121 \mathrm{~cm}^{2} / \mathrm{V} \mathrm{s}$ for electrons and holes, respectively. The devices were peeled off and transferred onto a polyethylene naphthalate foil to achieve flexible devices. CMOS inverters were also fabricated and show full output swing. (C) 2013 AIP Publishing LLC.

[http://dx.doi.org/10.1063/1.4811356]
\end{abstract}

Printed flexible electronics have received considerable attention because of the low-cost and applications in displays, sensors, and radio-frequency identification (RFID) tags on flexible substrates. Organic semiconductors offer a lowtemperature printing process of TFTs on plastic substrates. ${ }^{1}$ However, the carrier mobility and reliability are much inferior in comparison with $\mathrm{Si}$ devices. Indium Gallium Zinc Oxide (IGZO), as a metal oxide semiconductor, shows higher electron carrier mobility than that of organic semiconductors, but it is impossible to make both PMOS and NMOS TFTs using the same metal oxide. ${ }^{2}$ Transferring of CMOS-SOI chips $^{3}$ and amorphous $\mathrm{Si}(\mathrm{a}-\mathrm{Si}$ ) transistors on plastics by laser release $^{4}$ have been reported. However, the former has cost and technical issues since the limited size of the wafer and pick and place process, and in the latter, the electrical performance is low, although the laser release technique requires less cost. Printing of silicon, however, could provide high carrier mobility ${ }^{5,6}$ and at the same time the possibility of fabricating NMOS and PMOS TFTs in the same process on a large area substrate. Silicon can be printed using liquid silicon, ${ }^{5}$ which is a mixture of ultraviolet (UV)-irradiated cyclopentasilane (CPS) and a solvent. After forming a-Si by sintering spin-coated liquid-Si at $430{ }^{\circ} \mathrm{C}$ followed by dehydrogenation, poly-Si TFTs ${ }^{5}$ and single-grain Si TFTs ${ }^{6}$ have been fabricated with excimer-laser crystallization. Although mobilities of the resultant TFTs are much superior to those of organic TFTs, the dehydrogenation process with a temperature of more than $550^{\circ} \mathrm{C}$ is not suitable for polymeric substrates. In this paper, we report in the fabrication of singlegrain Si TFTs on a polyimide-coated substrate with a maximum process temperature of $350{ }^{\circ} \mathrm{C}$ using liquid-Si, which was deposited by doctor-blade coating, which is compatible with a roll-to-roll process. The carrier mobility is $460 \mathrm{~cm}^{2} / \mathrm{V}$

a) Telephone: +31 (0)15 27 87061. Fax: +31 (0)15 26 22163. E-mail: j.zhang@tudelft.nl $\mathrm{s}$ and $121 \mathrm{~cm}^{2} / \mathrm{V}$ s for electrons and holes, respectively. The devices were peeled off and transferred onto a Polyethylene naphthalate (PEN) foil to achieve flexible devices.

As shown in Fig. 1, first, a quasi-plastic substrate is prepared with spin-coating $10-\mu$ m-thick polyimide layer on top of a supporting crystalline $\mathrm{Si}$ substrate, which is subsequently cured at $400{ }^{\circ} \mathrm{C}$. Then, by the $\mu$-Czochralski process, ${ }^{7}$ small indentations called "grain-filters" $(100 \mathrm{~nm}$ diameter and $750 \mathrm{~nm}$ depth) are made in $4-\mu$ m-thick $\mathrm{SiO}_{2}$ deposited by plasma-enhanced chemical vapor deposition (PECVD) of tetraethyl orthosilicate (TEOS) at $350^{\circ} \mathrm{C}$ on the substrate, on which pure CPS (without solvents) is coated using a $\mathrm{Si}_{3} \mathrm{~N}_{4}$ doctor-blade in a low oxygen-level environment $(<10 \mathrm{ppm})$. To polymerize the layer and increase the boiling point, the coated CPS is irradiated with UV lamp for $20 \mathrm{~min}$. Then the polysilane layer was transformed to a-Si film with a thickness of $100 \mathrm{~nm}$ by a 1 -h thermal treatment at $350^{\circ} \mathrm{C}$ on a hot plate in the same environment. This temperature is lower than the $430{ }^{\circ} \mathrm{C}$ reported in the previous studies. ${ }^{5,6}$ The cross-section of a grain-filter completely filled with the a-Si (see supplemental material ${ }^{8}$ ). The Raman spectroscopy of the layer shows a broad peak at around $480 \mathrm{~cm}^{-1}$, which indicates that the film was converted into a-Si (see supplemental material ${ }^{8}$ ). Hydrogen concentration in the layer is measured to be 13 at. \% by Elastic Recoil Detection (ERD) (see supplemental material $^{8}$ ).

For crystallization of the a-Si film, a $\mathrm{XeCl}$ excimerlaser $(308 \mathrm{~nm}, 250 \mathrm{~ns})$ is employed. To avoid Si eruption due to hydrogen effusion during the laser irradiation, ${ }^{6}$ the sample is dehydrogenated by laser annealing using the same laser with multiple shots at lower energies. During the laser, the energy density is gradually increased from $300 \mathrm{~mJ} / \mathrm{cm}^{2}$ to $900 \mathrm{~mJ} / \mathrm{cm}^{2}$ with steps of $50 \mathrm{~mJ} / \mathrm{cm}^{2}$, while the number of shots for each energy density is decreased from 100 to 1 with a step of 10 shots. After laser annealing until $500 \mathrm{~mJ} / \mathrm{cm}^{2}$, the peak hydrogen concentration decreases 

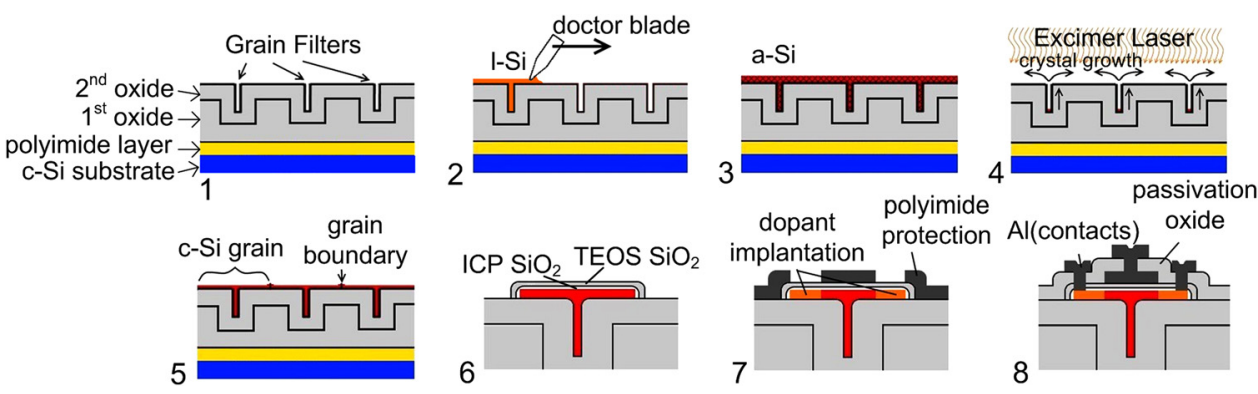

FIG. 1. Schematic of SG-TFT fabrication process with liquid-Si on polyimide substrate. from 13 at. $\%$ to 10 at. $\%$, while at the surface, the concentration decreases to 3 at. \% (see supplemental material ${ }^{8}$ ). After the dehydrogenation, the a-Si film is crystallized by the excimer-laser at room temperature with an energy density of $950 \mathrm{~mJ} / \mathrm{cm}^{2}$. Si grains are created on predetermined positions of the grain-filters with a maximum grain size of $3 \mu \mathrm{m}$, as can be seen in Fig. 2 .

TFTs are fabricated inside the grain with a process similar to as described in Ref. 6. After forming Si islands by patterning the $\mathrm{Si}$ film, $40 \mathrm{~nm}$ gate $\mathrm{SiO}_{2}$ is formed by inductively coupled plasma (ICP) oxidation at $250^{\circ} \mathrm{C}$ and additional $\mathrm{SiO}_{2}$ deposited by PECVD-TEOS at $350^{\circ} \mathrm{C}$. The SEM image of the silicon islands shows the channel covered by a single grain (see supplemental material ${ }^{8}$ ). After that the $\mathrm{Al}$ gate is deposited and source and drain regions are ionimplanted with boron and phosphorus using self-alignment by the gate. The impurities are activated by the excimerlaser. To prevent thermal damage to the polyimide substrate from the laser, an $\mathrm{Al}$ layer covers the area outside the gate, source, and drain. Passivation $\mathrm{SiO}_{2}$ deposition at $350{ }^{\circ} \mathrm{C}$ by PECVD TEOS and contact hole and $\mathrm{Al}$ pad formations complete the TFT fabrication. Both channel length and width are $1 \mu \mathrm{m}$. Finally, the polyimide substrate is etched away using oxygen plasma. The TFTs can now be peeled off from the crystalline $\mathrm{Si}$ wafer by an acrylic-based dicing tape and transferred to a $125 \mu \mathrm{m}$ thick flexible PEN foil using a glue made of polymers, as shown in Fig. 3. The transfer process is not necessary and the TFTs could be directly fabricated on the polyimide foil as the maximum process temperature was below $350{ }^{\circ} \mathrm{C}$. We have introduced the transfer process just because of the ease of handling and processing in our lab if the crystalline-Si substrate was employed as a carrier.

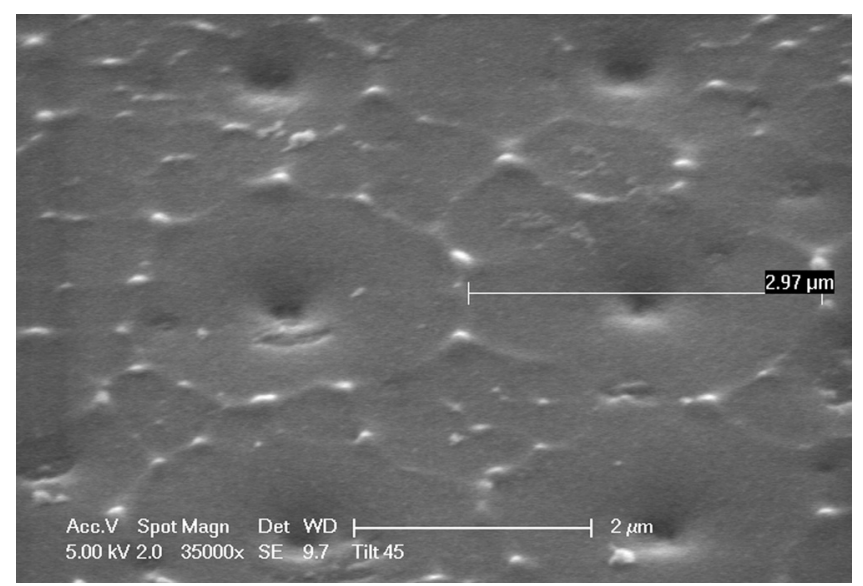

FIG. 2. SEM image of the crystallized grains at predetermined positions with a maximum diameter of $3 \mu \mathrm{m}$.
Figs. 4-6 show the transfer and output characteristics of the NMOS and PMOS TFTs. The carrier mobility estimated in the linear region with a low drain voltage is $460 \mathrm{~cm}^{2} / \mathrm{V} \mathrm{s}$ and $121 \mathrm{~cm}^{2} / \mathrm{V}$ s for electrons and holes, respectively. Table I summarizes the device characteristic values. The mobilities are much higher than those of the organic $\left(0.5 \mathrm{~cm}^{2} / \mathrm{V} \mathrm{s}\right.$, Ref. 1) and metal oxide ( $\sim 10 \mathrm{~cm}^{2} / \mathrm{V} \mathrm{s}$, Ref. 9) TFTs on a plastic substrate. The values are higher than poly-Si TFTs $\left(50 \mathrm{~cm}^{2} / \mathrm{V} \mathrm{s}\right.$, Ref. 10) as well because of the absence of the random grain-boundaries inside the channel. The leakage current is below $0.1 \mathrm{pA} / \mu \mathrm{m}$, which is lower than that of the polySi TFTs and suitable for display application. ${ }^{11}$ Fig. 7 shows the output characteristic of the CMOS inverter, with a full output swing $(4.997 \mathrm{~V}$ out of $5.000 \mathrm{~V})$ and with $\mathrm{V}_{\mathrm{TH}}$ of $2.14 \mathrm{~V}$. Table II presents the summary of the inverter characteristics.

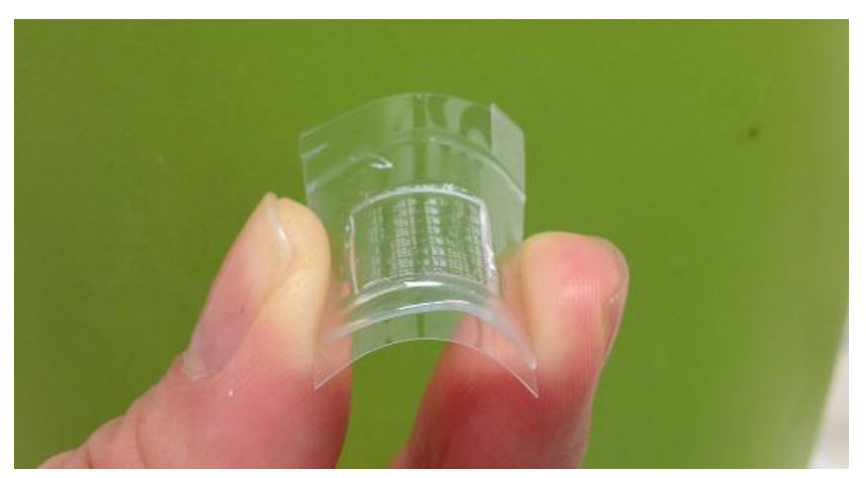

FIG. 3. Image of SG-TFTs on polyimide layer $\left(1 \times 1 \mathrm{~cm}^{2}\right)$ peeled off and transferred to a PEN foil.

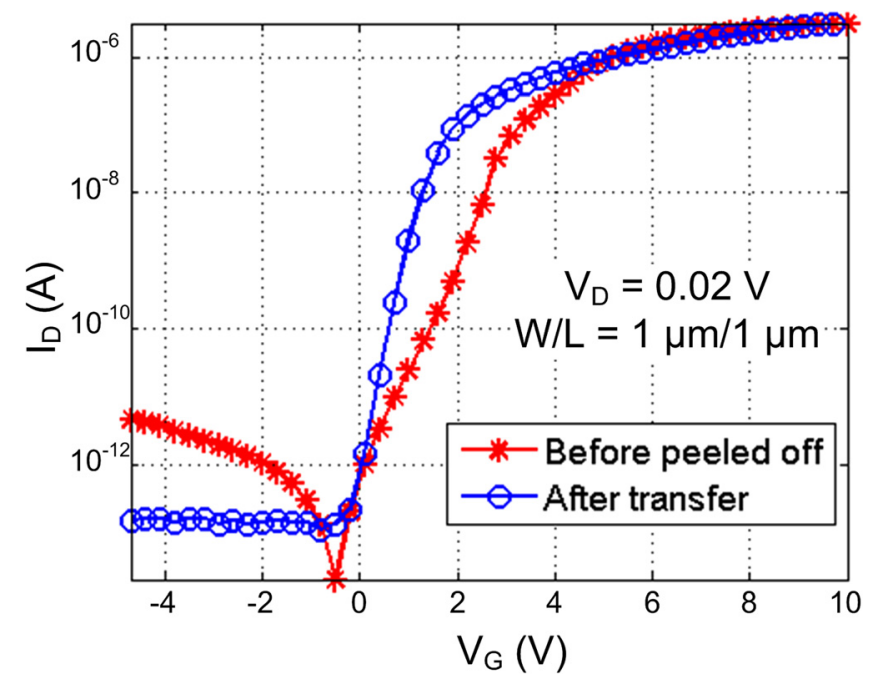

FIG. 4. Transfer characteristics of NMOS TFTs before the peeling-off and after the transfer. 


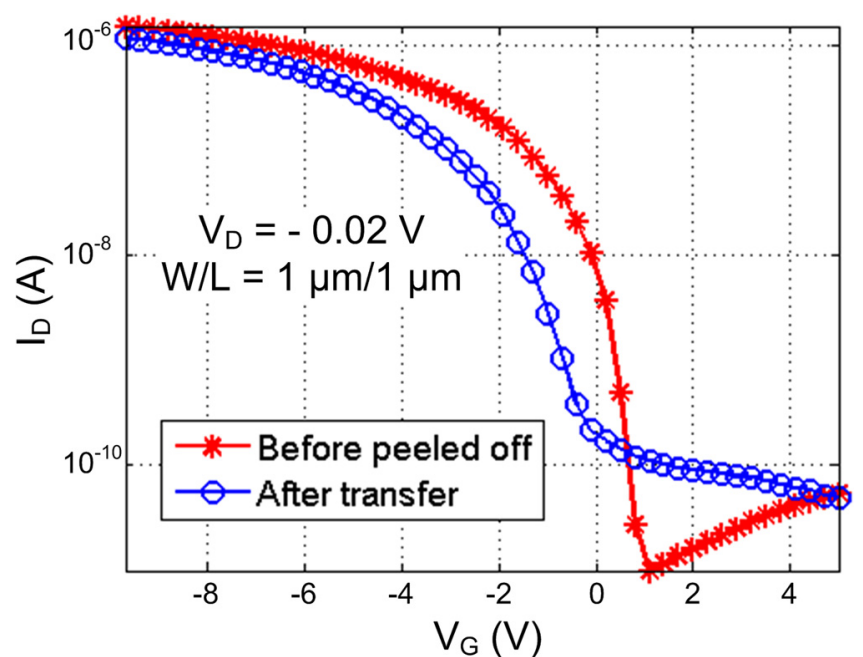

FIG. 5. Transfer characteristics of PMOS TFTs before the peeling-off and after the transfer.

After being peeled off with dicing tape and transferred to the flexible foil, the circuit still shows functioning transfer characteristics of NMOS and PMOS TFTs, as shown in Figs. 4 and 5 . The NMOS TFTs before and after being peeled off are measured on the same transistor, which also applies for PMOS TFTs and inverters. The estimated carrier mobility is $310 \mathrm{~cm}^{2} / \mathrm{V}$ s and $110 \mathrm{~cm}^{2} / \mathrm{V}$ s for electrons and holes, respectively, which is lower than before they were peeled off. The leakage current of NMOS transistors at high negative gate voltage decreases comparing to that before peeled off. The reason of the reduced carrier mobility is assumed to be the

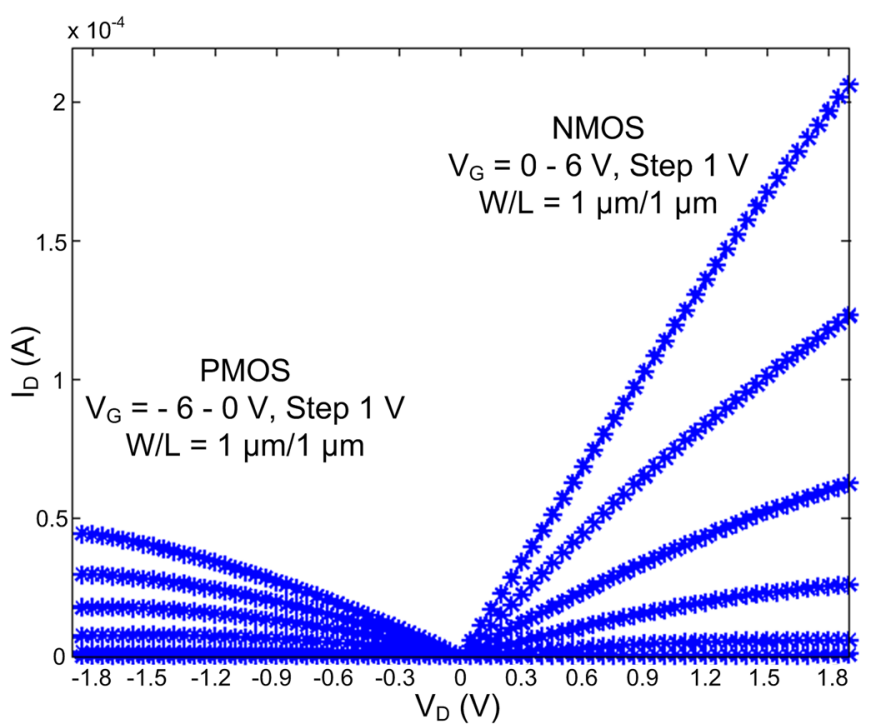

FIG. 6. Output characteristics of NMOS (a) and PMOS (b) TFTs before the peeling-off.

TABLE I. Summary of NMOS TFT and PMOS TFT characteristics.

\begin{tabular}{lcccc}
\hline \hline TFT & NMOS & NMOS after peeling & PMOS & PMOS after peeling \\
\hline$\mu_{\mathrm{FE}}\left(\mathrm{cm}^{2} / \mathrm{V} s\right)$ & 460 & 310 & 121 & 110 \\
$\mathrm{~V}_{\mathrm{TH}}(\mathrm{V})$ & 3.62 & 2.55 & -0.94 & -2.02 \\
$\mathrm{I}_{\mathrm{ON}} / \mathrm{I}_{\mathrm{OFF}}$ & $7 \times 10^{5}$ & $2 \times 10^{7}$ & $3 \times 10^{4}$ & $2.5 \times 10^{4}$ \\
$\mathrm{~S}(\mathrm{~V} / \mathrm{dec})$ & 0.3 & 0.26 & 0.24 & 0.67 \\
\hline \hline
\end{tabular}

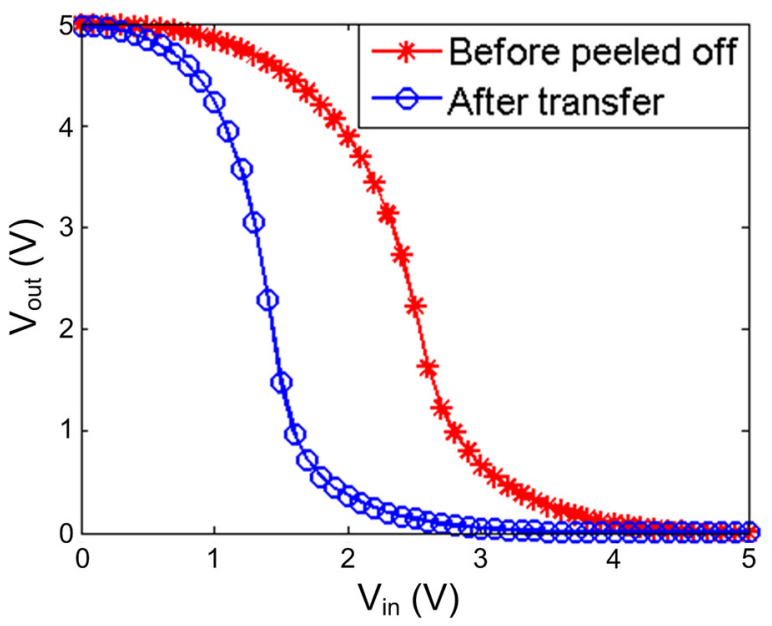

FIG. 7. Output characteristic of CMOS inverter with the ratio of 2 of W/L between PMOS and NMOS TFTs (red) before peeled off and (blue) after transfer.

TABLE II. Summary of the CMOS inverter characteristics.

\begin{tabular}{lcc}
\hline \hline Inverter & Before peeling & After peeling \\
\hline $\mathrm{V}_{\mathrm{TH}}(\mathrm{V})$ & 2.14 & 1.50 \\
$\mathrm{~V}_{\mathrm{OH}}(\mathrm{V})$ & 4.9972 & 4.9805 \\
$\mathrm{~V}_{\mathrm{OL}}(\mathrm{V})$ & 0.0096 & 0.0006 \\
$\mathrm{NM}_{\mathrm{H}}(\mathrm{V})$ & 2.3275 & 3.04 \\
$\mathrm{NM}_{\mathrm{L}}(\mathrm{V})$ & 1.3968 & 0.76 \\
\hline \hline
\end{tabular}

mechanical stress caused by the transfer process and/or stress during the measurement since the substrate is not rigid. The leakage current at $\mathrm{Vg}=-5 \mathrm{~V}$ becomes lower than $1 \mathrm{pA} / \mu \mathrm{m}$. Fig. 7 shows the output curve of the CMOS inverter on the flexible foil, with a $\mathrm{V}_{\mathrm{TH}}$ of $1.50 \mathrm{~V}$, a full output swing $(4.981 \mathrm{~V}$ out of $5.000 \mathrm{~V})$, and less-balanced noise margin compared to before being peeled off, since the threshold voltage of both NMOS and PMOS TFTs shifted to more negative values.

Amorphous Si was formed by doctor-blade coating and annealing of liquid-Si on a polyimide-coated substrate. With subsequent crystallization by excimer-laser, grains with a maximum diameter of $3 \mu \mathrm{m}$ were obtained. Single-grain $\mathrm{Si}$ TFTs fabricated inside the grain showed mobilities of 460 $\mathrm{cm}^{2} / \mathrm{V} \mathrm{s}$ and $121 \mathrm{~cm}^{2} / \mathrm{V}$ s for electrons and holes, respectively. The devices were peeled off and transferred to a flexible PEN foil, with carrier mobilities of $310 \mathrm{~cm}^{2} / \mathrm{V} \mathrm{s}$ and 110 $\mathrm{cm}^{2} / \mathrm{V}$ s, for electrons and holes, respectively. CMOS inverters were also fabricated and showed full output swing.

These results suggest that the approach presented in this paper can open a new route for achieving high-performance and flexible Si thin-film electronic devices on plastic with printing method compatible with a roll-to-roll process.

This work was sponsored by the Dutch Technology Foundation STW.

${ }^{1}$ T. Sekitani, U. Zschieschang, H. Klauk, and T. Someya, Nature Mater. 9, 1015 (2010).

${ }^{2}$ D. Raiteri, F. Torricelli, K. Myny, M. Nag, B. Van der Putten, E. Smits, S. Steudel, K. Tempelaars, A. Tripathi, G. Gelinck, A. Van Roermund, and 
E. Cantatore, in Proceedings of the IEEE International Solid-State Circuits Conference, ISSCC (2012), pp. 314-316.

${ }^{3}$ R. Dekker, P. G. M. Baltus, and H. G. R. Maas, IEEE Trans. Electron Devices 50, 747-757 (2003).

${ }^{4}$ H. Lifka, C. Tanase, D. McCulloch, P. Van de Weijer, and I. French, SID Int. Symp. Digest Tech. Papers 38, 1599-1602 (2007).

${ }^{5}$ T. Shimoda, Y. Matsuki, M. Furusawa, T. Aoki, I. Yudasaka, H. Tanaka, H. Iwasawa, D. Wang, M. Miyasaka, and Y. Takeuchi, Nature 440(6), 783-786 (2006).

${ }^{6}$ J. Zhang, R. Ishihara, H. Takagishi, R. Karajiri, T. Shimoda, and C. I. M. Beenakker, Tech. Dig. -Int. Electron Devices Meet. 2011, 14.5.1-14.5.4.

${ }^{7}$ R. Ishihara, P. C. van der Wilt, B. D. van Dijk, A. Burtsev, J. W. Metselaar, and C. I. M. Beenakker, Thin Solid Film 427, 77-85 (2003).
${ }^{8}$ See supplementary material at http://dx.doi.org/10.1063/1.4811356 for experimental data, Fig. S1 (cross-sectional SEM image of a grain-filter, completely filled with a-Si), Fig. S2 (Raman spectroscopy of the a-Si film formed with the liquid-Si at $350^{\circ} \mathrm{C}$ ), Fig. S3 (hydrogen concentration measured with ERD for the a-Si film before and after laser annealing at $500 \mathrm{~mJ} / \mathrm{cm}^{2}$ ), and Fig. S4 (SEM image of patterned silicon islands).

${ }^{9}$ W. C. Germs, W. H. Adriaans, A. K. Tripathi, W. S. C. Roelofs, B. Cobb, R. A. J. Janssen, G. H. Gelinck, and M. Kemerink, Phys. Rev. B 86, 155319 (2012).

${ }^{10}$ A. Pecora, L. Maiolo, M. Cuscuna, D. Simeone, A. Minotti, L. Mariucci, and G. Fortunato, Solid-State Electron. 52, 348-352 (2008).

${ }^{11}$ S. Y. Yoon, N. Young, P. J. van der Zaag, and D. McCulloch, IEEE Electron Device Lett. 24, 22-24 (2003). 